SHS Web of Conferences 10, 00040 (2014)

DOI: $10.1051 /$ shsconf/20141000040

C Owned by the authors, published by EDP Sciences, 2014

\title{
The control of human thermal comfort by the smart clothing
}

\author{
I. Sahta, I. Baltina, J. Blums, and V. Jurkans
}

Riga Technical University, Latvia

\begin{abstract}
Generally, human thermal comfort depends on combinations of clothing structure and chemical nature of fibers, external conditions and factors related to wearer. Thermal comfort of a clothing system is associated with thermal balance of body and its thermoregulatory responses to the dynamic interactions with the clothing and the environment, and can be quantified in terms of Met and Clo units. One of the important functions of clothing is to provide adequate thermal comfort for wellness and high performance. To do this research, clothing with an integrated human microclimate regulating electrical system has been developed. The clothing contains: Peltier elements, which provide cooling effect; electronic control system with heat sensor - thermistor, which controls the optimal operating parameters, and energy source. The aim of experiments is to verify, how the cooling system, integrated in the clothes, influences indicators of the human microclimate. For this reason, the experiments of wearing by the appropriate operating conditions are carried out by measuring temperature changes in different locations in space between the body and clothes during activities. The analysis of experimental results reveals the system's operational efficiency as well as the negative impact of non-evaporative materials on the possibility of vapour removal through the garment surface.
\end{abstract}

\section{Introduction}

Human microclimate is an important factor in maintaining of optimal capacity for work and feeling of comfort. High heat conditions may cause health problems, as well as psychiatric problems, which can lead not only to the reduction in quality of work, but also to the human vital organ dysfunction.

The concept "human thermal comfort" is not unequivocal explainable. The human being has its own dynamics, thereby clothing comfort is a subjective feeling and it is quite difficult to define all factors which can affect this feeling. Generally, human thermal comfort depends on combinations of clothing structure and chemical nature of fibers, external conditions (ambient temperature, humidity etc.) and factors related to wearer (metabolism, physical activities etc.). Thermal comfort of a clothing system is associated with the thermal balance of the body and its thermoregulatory responses to the dynamic interactions with the clothing and the environment, and can be quantified in terms of Met and Clo units. One of the important functions of clothing is to provide adequate thermal comfort for wellness and high performance.

During this research, the smart clothing with an integrated human microclimate regulating electrical system was developed. To verify microclimate regulatory clothing prototype with electrical cooling system compliance with the general requirements to the garment, it is scheduled to assess the

This is an Open Access article distributed under the terms of the Creative Commons Attribution License 4.0, which permits unrestricted use, distribution, and reproduction in any medium, provided the original work is properly cited. 
physiologically - hygienic point of wearing by the appropriate operating conditions, during activities by measuring temperature changes in different locations in space between the body and clothing layers.

\section{Analysis of factors affecting the human thermal comfort}

Factors which can influence human comfort can be divided into three categories:

1. Factors related to wearer (metabolism of person, age, physical fitness of body, level of health, mental and types of activities);

2. Clothing structure and chemical nature of fibers (fiber and yarn types, fabric structure, mechanical and thermal properties of fabric, clothing design, fitting);

3. External Conditions (moisture, ambient and radiant temperature, wind speed etc.) [7].

The thermal exchange between body and environment takes place through heat conduction, convection and radiation, but the exchange of body moisture takes place through perspiration and sweating. Heat and moisture transport processes are influenced both in the form of diffusion, and by ventilation through the garment fabric caused by the movement of human in the environment [8]. The clothes create a certain microclimate around the human body, which affects human feeling of comfort. As the one of the most important parameter of garment should be mentioned the air temperature between the body and the first layer of clothing - underwear. The optimum level of this temperature is determined by human physical activities [9].

The thermal comfort of a clothing system is associated with the thermal balance of the body and its thermoregulatory responses to the dynamic interactions with the clothing and the environment [1]. Environment influences on human thermal comfort not only through the air temperature, air velocity and water vapor pressure, but also through the solar radiation, barometric pressure, precipitation or radiant heat flux. The heat balance of the human body includes the energy metabolism, external mechanical work, respiratory heat exchange, evaporative heat exchange, radiation heat exchange, convective heat exchange and conductive heat exchange. It is common to consider the rate of energy change per unit time and body surface area $-\mathrm{W} / \mathrm{m}^{2}$ (usually expressed in Joule or Watt) [6]. Ambient temperature, radiant temperature, humidity and air movement are the basic environmental variables while the metabolic rate and clothing's insulation and moisture permeability provides the behavioral variables affecting human sensation and response to environmental temperature. For example, an increase of $17.5 \mathrm{~W}$ in metabolic rate is equivalent to a $1^{\circ} \mathrm{C}$ increase in ambient temperature [4].

The thermal comfort is also affected by such individual human factors as skin temperature, skin wittedness or the general state of body's health etc.

Commonly, for the explanation of factors affecting thermal comfort are used:

- Metabolic rate

The metabolic rate, or human body heat production, is measured in the unit "Met", where the metabolic rate of a relaxed seated person is " 1 " Met $\left(1 \mathrm{Met}=58 \mathrm{~W} / \mathrm{m}^{2}\right)$. Knowing that the mean surface area of the human body is approximately $1.8 \mathrm{~m}^{2}$, the total metabolic heat for a mean body can be calculated by multiplying with the surface area of a person. In this case the total heat from a relaxed seated person would be $104 \mathrm{~W}\left(58 \mathrm{~W} / \mathrm{m}^{2} \times 1.8 \mathrm{~m}^{2}=104 \mathrm{~W}\right)$ [6]. Metabolic energy production is affected by muscular work. For example, the running in $15 \mathrm{~km} / \mathrm{h}$ is expressed in $550 \mathrm{~W} / \mathrm{m}^{2}$ or 9.5 Met. Metabolic energy production may vary from $100 \mathrm{~W} / \mathrm{m}^{2}$ in light work to $500 \mathrm{~W} / \mathrm{m}^{2}$ or even higher in sport activities and during rescue work (firefighting) for short time (1-2h).

- Thermal insulation

Clothing thermal insulation is described as the resistance to heat transfer by convection, radiation and conduction. It is determined by the properties of fiber materials and fabric construction, the layers of 
Int. Conf. SOCIETY. HEALTH. WELFARE.

trapped air in the fabric and the air layers between fabrics and fabric layers [6]. The most important factor is the thickness of trapped, still air layers, because the air is known as one of the best heat insulator. The thermal insulation is measured by the lateral thickness of the total clothing ensemble and usually it is expressed by the unit "Clo". Approximately $1 \mathrm{Clo}\left(1 \mathrm{Clo}=0.155 \mathrm{~m}^{2}{ }^{\circ} \mathrm{C} / \mathrm{W}\right)$ corresponds to a person wearing a typical business suit - a normal indoor clothing with jacket, trousers and vest - in a normally ventilated room $(0.1 \mathrm{~m} / \mathrm{s}$ air velocity $)$ at the air temperature of $21^{\circ} \mathrm{C}$ and relative humidity less than $50 \%$. It is assumed that on an average $24 \%$ of the metabolic heat is lost through evaporation from the skin and remaining of $38 \mathrm{kcal} / \mathrm{m}^{2} * \mathrm{~h}$ should be transmitted through the clothing assembly by conduction, convection and radiation. The comfortable mean skin temperature is $33^{\circ} \mathrm{C}$. Zero " 0 " Clo corresponds to a naked person. Very thin fabric layers of clothing varies from 0.02 to 0.20 Clo (for example, underwear), thick fabric layers varies from $0.20-0.50$ Clo (for example, sweater), but coats, overjackets or overtrousers are expressed with $0.50-0.70 \mathrm{Clo}(0.70 \mathrm{Clo}$ for parka) units.

\section{Clothing for thermoregulation}

The thermoregulatory clothing depending on the level of their "intelligence" of thermoregulation function integrated into textile, respectively, ability to respond to environmental parameter changes, could be divided into:

- Passive thermoregulation

There could be mentioned conventional textiles, such as silk or wool - fibers able to warm or cool depending on environmental conditions; textiles with special fibers (for example, hole fibers for warming) or special textile structure (for example, three-dimensional structure) constructions; as well as functional multilayer clothing systems: $1^{\text {st }}$ layer - good vapor and air permeability; $2^{\text {nd }}$ layer - warmth isolation; $3^{\text {rd }}$ layer - protection from environmental conditions: wind, rain.

- Active thermoregulation

Smart materials, such as materials with phase changing material's capsules (PCM-capsules) changing their state of aggregation due to changes in ambient temperatures keep the balance of human body micro-climate temperature. Textiles with integrated electrical/electronic systems for heating or cooling, with sensors to measure temperature changes in space of human body microclimate, for example, knitted heating system of conductive yarns or in the clothing embedded heating elements.

Microclimate regulatory function of clothing, mostly in the form of a commercial product, is already known as a heat producing function, less popular is cooling function. Different cooling systems, operating at different cooling principles - thermodynamic methods such as Erikson cycle, Peltier effect, Thomson effect, the optical cooling, as well as a variety of refrigerants and agents [2] can be integrated in clothes. As potential possible variants for commercial cooling clothing could be mentioned:

- garment with integrated cooling fluid flow,

- cooling with air flow,

- cooling with ice or gel packs,

- evaporative cooling technology a. o.

These products have some deficiencies, such as: lack of mobility, when the reservoir and the pump for fluid or air flow are stationary, possibility of liquid condensation in space between the body and clothing, high weight ( $\sim 4 \mathrm{~kg}$ ) of clothing, temporary effect (1 to $13 / 4$ hours), prolonged constant coldness can cause vasoconstriction effect. 

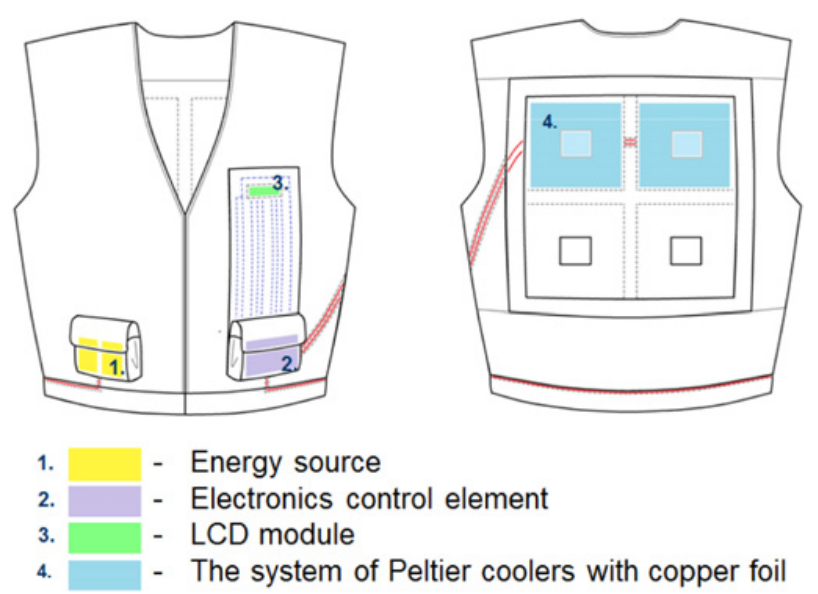

Figure 1. Concept of microclimate regulatory vest.

\section{Materials and concept of microclimate regulatory vest}

The purpose of this study is to create a wearable microclimate control system, which would not contain liquid or gaseous fluids, but the cooling function is based on the heat conduction processes in solid states.

As a cooling element there is used electro-thermal converter (thermo-battery) - Peltier element, which operation is based on Peltier (J. Peltier (1785 to 1845)) effect: element by the current flowing through it creates a temperature difference or by the temperature difference causes a current flow [3]. Generally the cooling system of microclimate regulatory vest includes: two to four Peltier elements located on the back part of clothing; energy source and electronics control element placed into pockets on the forepart of vest; LCD module and textile buttons to control system's operational parameters are integrated in the textile panel sewn on the forepart of clothing (Fig. 1).

A heat created by the current on the outer surface of Peltier element is absorbed by the copper foil radiator attached to hot surface of element; the cold surface of element is disposed to the inner side of vest.

METHOD. The aim of experiment is to find out how the cooling system of Peltier elements integrated into clothing affects indicators of human micro-climate. Such physiological factors of human body expressing the human comfort are measured: temperature on the skin; temperature between the $1^{\text {st }}$ clothing layer - undershirt - and $2^{\text {nd }}$ layer - cooling vest; temperature on the cooling system; as well as moisture (electrical resistivity) on the skin. Sensor placements are shown in Figure 2.

The sensors for temperature and humidity measurements are placed as follows (Fig. 2): back part of $1^{\text {st }}$ clothing layer: moisture sensors $15,16,17$ on the skin under the shirt; temperature sensors: 11,12 on the skin; the others are placed between $1^{\text {st }}$ layer - shirt - and $2^{\text {nd }}$ layer - cooling vest.

The temperature and moisture measurements were carried out during two experiments with $30 \mathrm{~min}$ (system activation is set to $27^{\circ} \mathrm{C}$ under the system of Peltier element) and 13 min (system activation is set to $29^{\circ} \mathrm{C}$ under the system of Peltier element) long time running. Conditions of physical activity (Fig. 3): jogging track slope-5\%; speed $-7 \mathrm{~km} / \mathrm{h}$; room temperature $20^{\circ} \mathrm{C}$; relative air humidity $-59 \%$.

\section{Results and discussion}

The measurement results showed difference between both experiments: during 30 min long jogging the system switched on and began to cool already at 9 min of physical activity (when the temperature 
Int. Conf. SOCIETY. HEALTH. WELFARE.

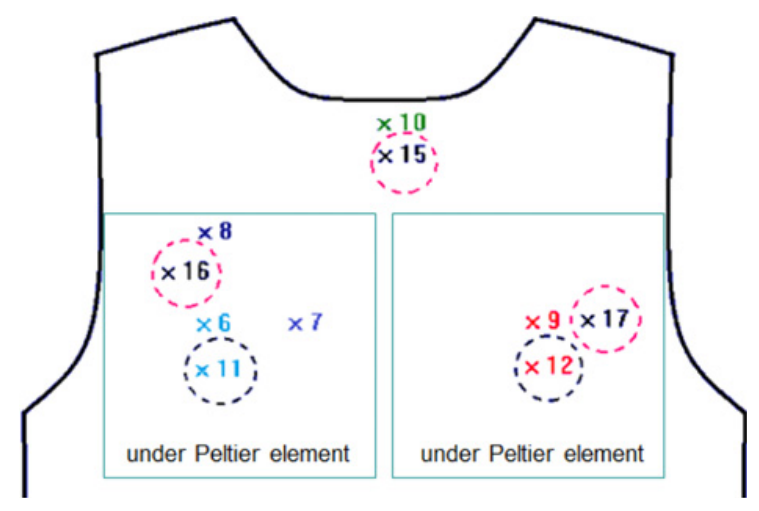

Figure 2. The placement of sensors for temperature and humidity measurements.
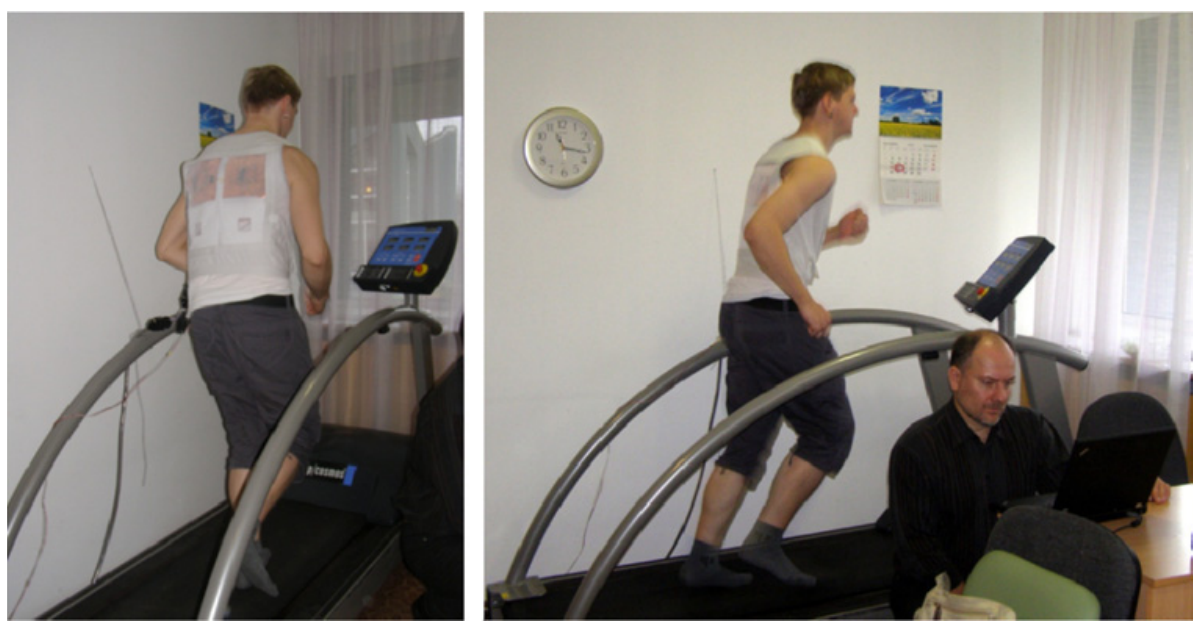

Figure 3. Measurements during jogging.

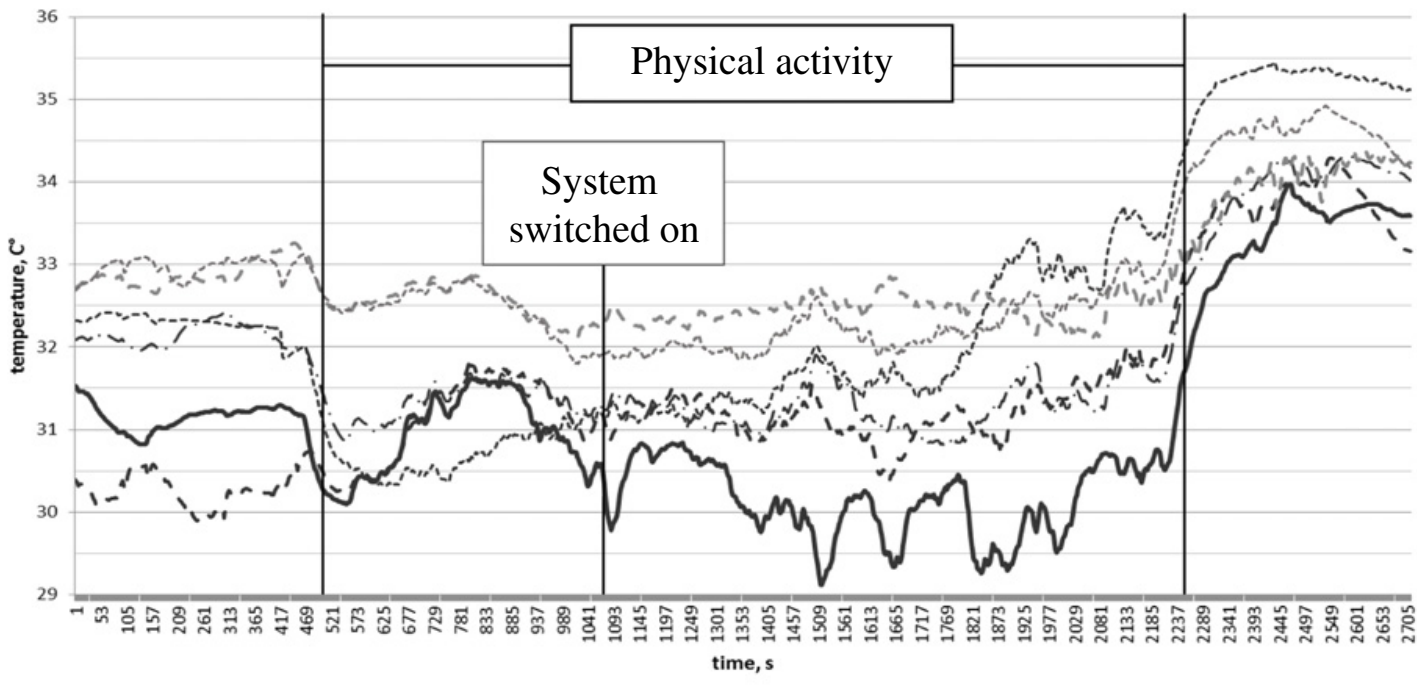

Figure 4. Temperature measurement results during $30 \mathrm{~min}$ long jogging.

$$
\text { 00040-p.5 }
$$




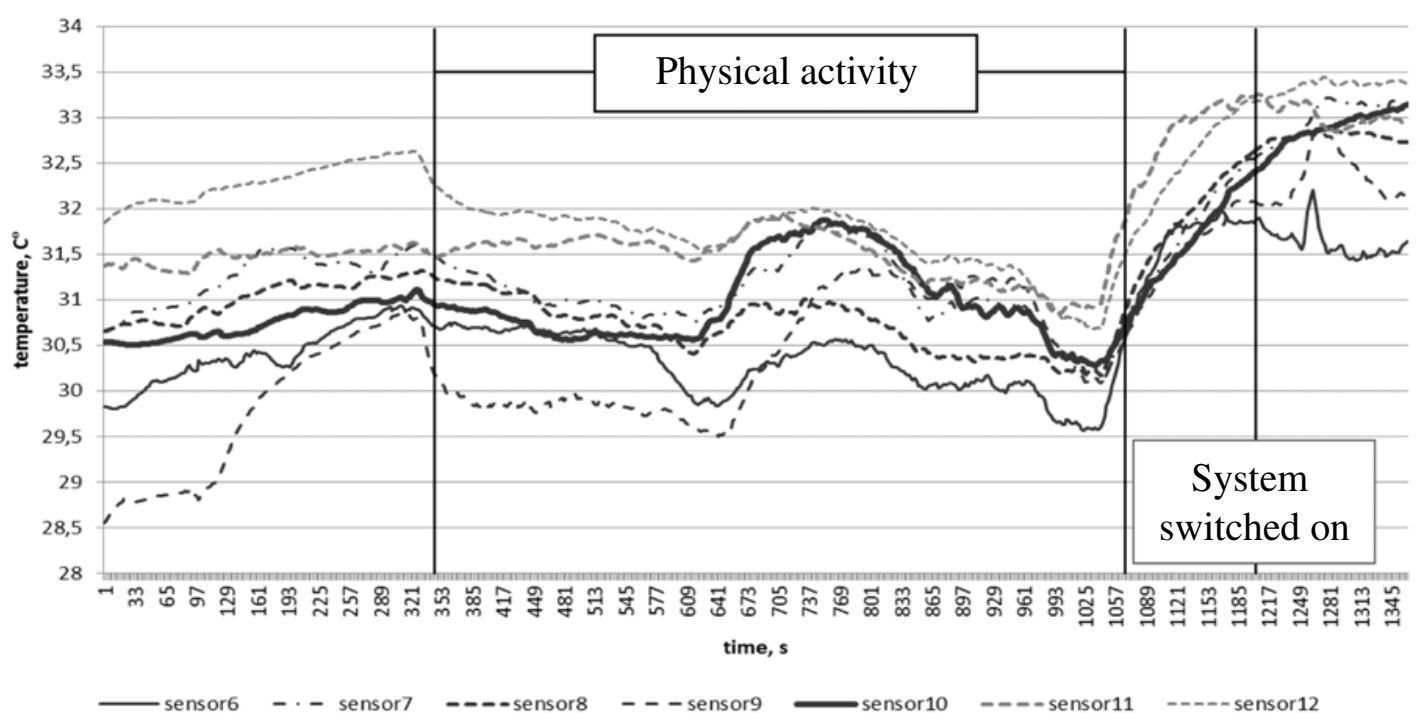

Figure 5. Temperature measurement results during 13 min long jogging.

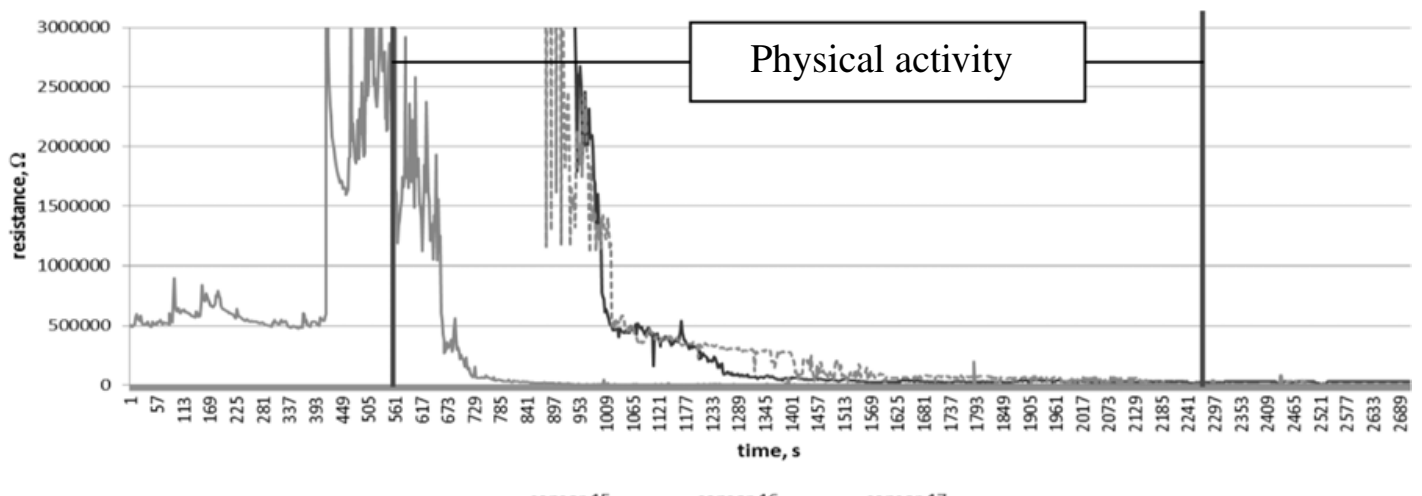

Figure 6. Moisture measurements during 30 min long jogging.

of $27^{\circ} \mathrm{C}$ under the Peltier element was reached) and at all points of measurement temperature is smoothening (Fig. 4).

During the experiment of 13 min long jogging, the system was activated only after running, by reaching a temperature of $29^{\circ} \mathrm{C}$ as it is shown in the diagrams and temperature during physical activity is uneven-increase and decrease of $\sim 1^{\circ} \mathrm{C}$ (Fig. 5).

Comparing both experiments the most rapid decrease of temperature was observed after jogging by experiment with cooling during the physical activity as it was with experiment with cooling after jogging.

Moisture measurements showed similar results in both experiments: sensors (sensors 16 and 17) under the system of Peltier element with attached copper foil fixed the moisture already at the beginning of jogging, whereas the sensor on the neck fixed moisture later, only at the middle of physical activity.

Moisture measurement results indicate copper foil negative impact on the moisture removal. 
Int. Conf. SOCIETY. HEALTH. WELFARE.

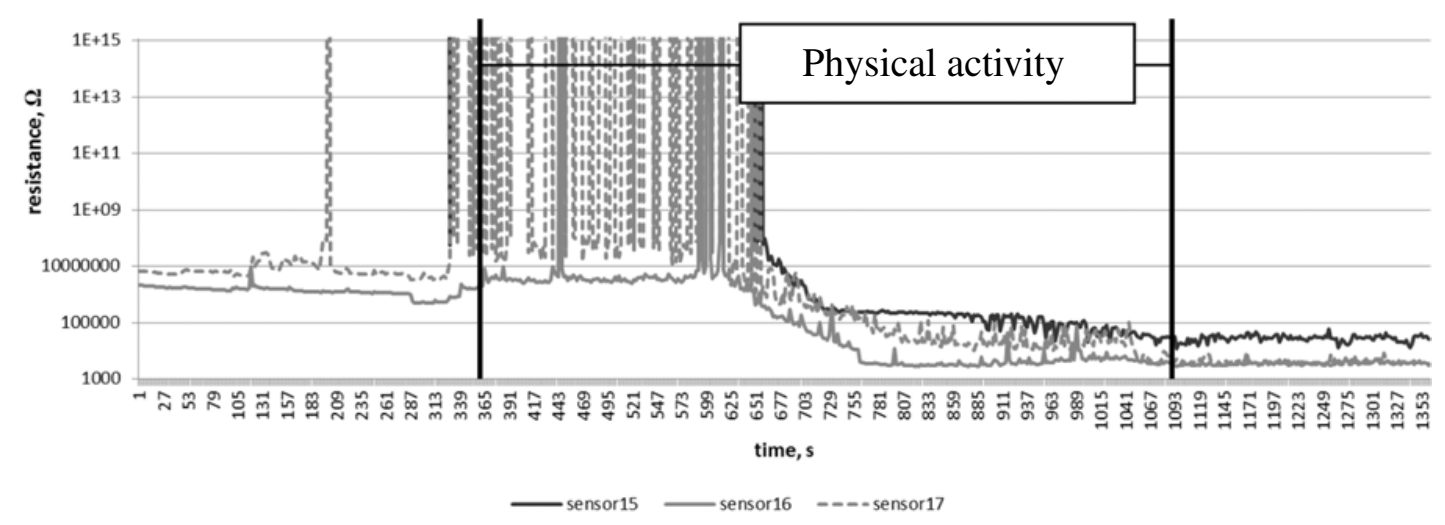

Figure 7. Moisture measurements during $13 \mathrm{~min}$ long jogging.

\section{Conclusions}

The concept "human thermal comfort" is not unequivocal explainable and could be influenced by different individual human factors, environmental conditions and clothing fiber materials and fabric structure.

The analysis of human microclimate temperature modelling experiment results enable to carry out common conclusions, such as: the cooling system is able to balance the temperature of human microclimate during physical activities, but Peltier element and its attached copper foil, has a negative impact on the removal of moisture vapor through the garment surface and that can cause additional temperature rise in the space of microclimate under the Peltier element and it's attached copper foil. The most changes in temperature are observed under the Peltier elements.

The experiment results demonstrate the efficiency of system operation, but the difference in results indicates dependence on personal human factors (such as metabolism of person, physical fitness of body, level of health) and their influence on the measurement results.

\section{References}

[1] Apurba, D., Alagirusamy, R. (2010). Science in Clothing Comfort, Cambridge: Woodhead, 175 pp.

[2] Bansevičius, R., Račkiene, R., Virbalis, J. A. (2007). The body Cooling System Integrated into the Clothes. Electronics and electrical engineering. 5 (77), pp. 3-6

[3] Colinge, J. P., Colinge, C. A. (2002). Physics of semiconductor devices. Dordrecht: Kluwer Academic Publishers, $436 \mathrm{p}$.

[4] Epstein, Y., Moran, D. S., Thermal Comfort and the Heat Stress Indices. Industrial Health. 44(3), pp. 388-398

[5] Havenith, G., Holmer, I., Parsons, K. (2002) Personal factors in thermal comfort assessment: clothing properties and metabolic heat production. Energy and Buildings. 34(6), pp. 581-591

[6] Holmer, I. (2006). Protective Clothing in Hot Environments. Industrial Health. 44 (3), pp. 404-413

[7] Mangat, M. M. A. (2010). Clothing Comfort - A Combination of Objective and Subjective Evaluation, Liberec: Technical University Liberec, 74 pp.

[8] Pan, N., Gibson, P. (eds.) (2006). Thermal and Moisture Transport in Fibrous Materials, Cambridge: Woodhead, 632 pp.

[9] Делль, Р. А., Афанасьева, Р. Ф., Чубарова, З. С. (1979). Гигиена одежды [Нygiene of Clothing]. Москва: Легкая индустрия, 143 с. (in Russian). 